\title{
Use of the Planning Outreach Liaison Model in the Neighborhood Planning Process: A Case Study in Seattle's Rainier Valley Neighborhood
}

\author{
Molly Oshun, ${ }^{1}$ Nicole M. Ardoin, ${ }^{2}$ and Sharon Ryan $^{3}$ \\ ${ }^{1}$ Civil and Environmental Engineering, Stanford University, 7910 Swartz Avenue, Sebastopol, CA 95472, USA \\ ${ }^{2}$ School of Education and Woods Institute for the Environment, Stanford University, 485 Lasuen Mall, Stanford, CA 94305, USA \\ ${ }^{3}$ Sharon Ryan Communications, 29 President Avenue, Providence, RI 02906, USA
}

Correspondence should be addressed to Nicole M. Ardoin, nmardoin@stanford.edu

Received 6 May 2011; Revised 31 August 2011; Accepted 22 September 2011

Academic Editor: Michelle Thompson-Fawcett

Copyright ( $) 2011$ Molly Oshun et al. This is an open access article distributed under the Creative Commons Attribution License, which permits unrestricted use, distribution, and reproduction in any medium, provided the original work is properly cited.

\begin{abstract}
Our study examines a nontraditional engagement process employed by the City of Seattle during neighborhood plan updates. Adapting the trusted advocates model from the public health field, the city hired planning outreach liaisons (POLs) from 13 diverse community groups to solicit input from traditionally underrepresented residents. To explore the efficacy of this approach, we collected data through interviews with residents, neighborhood leaders, community development firm employees, university researchers, and municipal staff; a review of planning documents; observation at planning meetings. We found that the POLs effectively engaged underrepresented groups-including more than 1,200 stakeholders-particularly those characterized as selforganized, centralized or having strong social networks and were important in the advancement of democratic principles. Greater transparency by the city about process goals and constraints, along with strategies to address power issues, may have facilitated better communication and relationship building among the city, newly enfranchised residents, and the "usual suspects."
\end{abstract}

\section{Introduction}

Neighborhood planning is a process whereby members of a community participate in a visioning process to guide future development in their neighborhood. Interest in communitybased neighborhood planning has grown significantly in the past 50 years [1], with one intended outcome being to engage a broader range of voices, interests, needs, and perspectives into a process that affects the future physical, economic, and social makeup of a place [2]. A number of studies (e.g., [3-5]) have demonstrated the importance of inclusive and collaborative discussion in developing effective public policy and building community support for implementation of any plan. Participatory planning has done much to bring "new actors" such as blacks, latinos, and the poor [1] and "multiple voices and values into the planning of cities, neighborhoods, and environments" in past decades [2]; however, the process of involving citizens and representing their views fairly in decision-making remains challenging $[6,7]$. Tra- ditional avenues for soliciting public input often limit the participation of people from disadvantaged communities who may experience barriers related to English language proficiency, childcare needs, knowledge of planning procedures, and familiarity with participatory democracy [1]. Additional barriers may result from public apathy; new or short-term residents may struggle to see the value in longterm planning for their community [8]. Finally, institutional barriers, exemplified by government agencies and other institutions that may have inflexible and outdated structures, may also make public participation difficult to incorporate meaningfully [2].

Earlier critiques of public planning in Seattle, Washington, focused on a lack of participant diversity during the original neighborhood plans. Though the city has a strong history of public engagement in the planning process, many community members and city staff expressed concern that a small group of citizens exerted disproportionate influence over development of the plans. Some cited socioeconomic 
and linguistic barriers to more comprehensive participation; others identified resident apathy toward long-term planning [9].

Our study examines the use of an innovative model for outreach and engagement recently piloted during neighborhood plan updates in the Rainier Valley neighborhood of Seattle. The goal was to reach and involve a greater number of historically underrepresented citizens in the neighborhood planning process and, ultimately, produce more representative plans through which the community might retain its rich cultural diversity during anticipated development. In an effort to improve outreach to, and participation of, traditionally underrepresented cultural, ethnic, and linguistic groups, the City of Seattle employed the trusted advocates model, adapted from the public health field, and developed by the Annie E. Casey Foundation. City administrators contracted 13 "trusted advocates" in the form of planning outreach liaisons (POLs) to act as a bridge between the city and "communities of color, immigrants and refugees, the disabled, seniors and youth" [10]. The POL process was conducted simultaneously with Seattle's traditional public outreach process, which consisted of a series of open house public meetings in the Rainier Valley through which the city solicited public input and feedback on the development of the three neighborhood plans. During such meetings, little attempt was made to distinguish between stakeholders or encourage direct community oversight of plan development.

This paper first details the organizational structure of the outreach process coordinated by the POLs as described by participants, city staff, and observers; we collected data on these perspectives through a series of interviews conducted in the fall of 2009. Additional information comes from a review of city planning documents and direct observation at two open house meetings. We explore perceptions and awareness of the POL model within the broader community of neighborhood stakeholders, as well as its relative success compared to traditional outreach vehicles used during the process. Next, we examine the importance of outreach to underrepresented communities in the context of plan implementation and democratic development, and we ground our findings in theory related to participatory processes and the trusted advocate model found in the literature. Finally, we consider implications for use of this model in other public participation processes and suggest recommendation for maximizing its effectiveness in neighborhood planning. The study's limitations are presented and potential areas of future research suggested.

\section{Literature Review}

Citizen participation has received increased attention since the 1950s, "with the underlying assumption that if citizens become actively involved as participants in their democracy, the governance that emerges from this process will be more democratic and more effective" [11]. Indeed, participation is considered to be a crucial element in our democratic process, capable of holding the government accountable to the public and, in the case of urban planning, creating an appropriate vision to guide development $[4,12]$.
Engaging a diverse citizenry in long-term planning is frequently problematic as disadvantaged communities often experience barriers to participation, including language barriers, time restraints, lack of adequate knowledge of political systems, and lack of politically favorable relationships with those in power, among others $[1,2,13]$. Moreover, the traditional model of planning can be daunting: planners often use jargon and theory that may be inaccessible to community members, and typical timelines for implementation exceed any relevant temporal horizon for many young residents and renters $[14,15]$.

Despite the challenges associated with engaging diverse stakeholders in planning, studies suggest that inclusive processes may contribute to the creation of more robust plans with a greater likelihood of long-term success in both implementation and sustainability $[3,16]$. Brody et al. [16] found that mandates requiring local governments to solicit public involvement resulted in enhanced citizen participation, while also affecting the level to which planners and city officials considered public input when designing planning policies and procedures. Research further suggests that participation of a broad swath of community members can strengthen engagement in the democratic process and enhance support for local government [13]. Moreover, culturally appropriate engagement of diverse audiences can encourage ongoing participation in implementation of development plans and improve communication between experts and community members $[5,17]$.

However, if public plans are designed using an inclusive process but are inequitable or inept in their execution, community members may be nominally engaged in the short term but fail to be engaged meaningfully in the long term [18]. Participatory planning should not only seek to understand and articulate community differences but also provide inventive ways for "interaction and negotiation of competing visions, interests, values, and identities" [2]. To ensure effective and comprehensive implementation of a community plan, research suggests that the development of relationships between and amongst members of existing local networks is essential [19]. Consensus building requires developing relationships among diverse stakeholders to facilitate understanding and to improve the quality of decision making. Innes [20] notes that consensus building "requires a full range of stakeholders, meaningfulness to participants, mutual understanding, dialogue with equal opportunity to participate, self-organization, and accessible information."

Among the tools and mechanisms available for ensuring participation and negotiating cooperative action is the use of trusted and respected community leaders, advocates, or mediators. Models of engagement that emphasize empowerment of local leaders who remain embedded in diverse social networks have been associated with feminist theory [21], community-based conservation theory [22], and the public health field $[23,24]$.

In the healthcare field, the use of "indigenous, trusted and respected" community health workers, who serve as bridges between their communities and health providers, has proven effective in expanding heath care services to the underserved [24]. These workers possess indigenous 
qualities of the target communities including verbal and nonverbal language skills; racial and ethnic qualities of the communities; social and environmental familiarity [25]. Their purpose is to "empower community members to identify their own needs, develop a plan that is right for them, and implement the solutions" [24]. While trusted advocates from within the community are able to establish critical connections and offer "insights into the community dynamics, cultural beliefs, and practices," practitioners caution against assuming that trusted advocates are sensitive to cultural issues solely by virtue of being a member of that group [26]. Rather, many variables, including age, economic status, social class, and experience must be taken into account when recruiting advocates [26].

According to the Annie E. Casey Foundation [23], one of the early premises of the trusted advocates model was that "people working together on projects build strong relationships." Trusted advocates can help build these strong relationships and facilitate collective decision making by performing a number of key functions including (1) outreach and engagement to link community members to programs, resources and supports, (2) identifying community needs, concerns and preferences, (3) building social networks and connecting people within communities, (4) representing communities in decision-making processes, and (5) organizing and coordinating activities around specific issues [27]. Ultimately, resident engagement processes can be considered successful when there are "resident voices at decision-making tables, with competence and confidence to participate fully in the deliberations and who understand that they are connected to constituencies in their neighborhoods to whom they are accountable" [27]. This paper explores the efficacy of this model in achieving these outcomes in city planning in Seattle, thereby expanding the body of knowledge in this area of study.

\section{Study Site}

Our study focuses on neighborhood plan updates in three neighborhoods of the Rainier Valley in Seattle, Washington (see Figure 1). The neighborhoods of North Beacon Hill, North Rainier Valley, and Martin Luther King Jr. at Holly Street (Othello) are located in the southeast sector of the city, a region traditionally characterized as a center of cultural and ethnic diversity in a largely white city [28]. In 2000, the southeast area was home to some of the highest percentages of Asian, African American/Black, and Hispanic/Latino populations in Seattle and had the highest concentration of foreign born individuals in the city as well as high percentages of those who spoke languages other than English at home [29]. According to the 2000 Census, $69.8 \%$ of Southeast Seattle residents were people of color and $28.6 \%$ were classified as "poor" or "near poor" [28], and more than $35 \%$ of residents speak languages other than English [30].

Anecdotal evidence and previous studies suggest that neighborhood characteristics, such as availability of affordable housing, commercial space, and service-industry jobs,

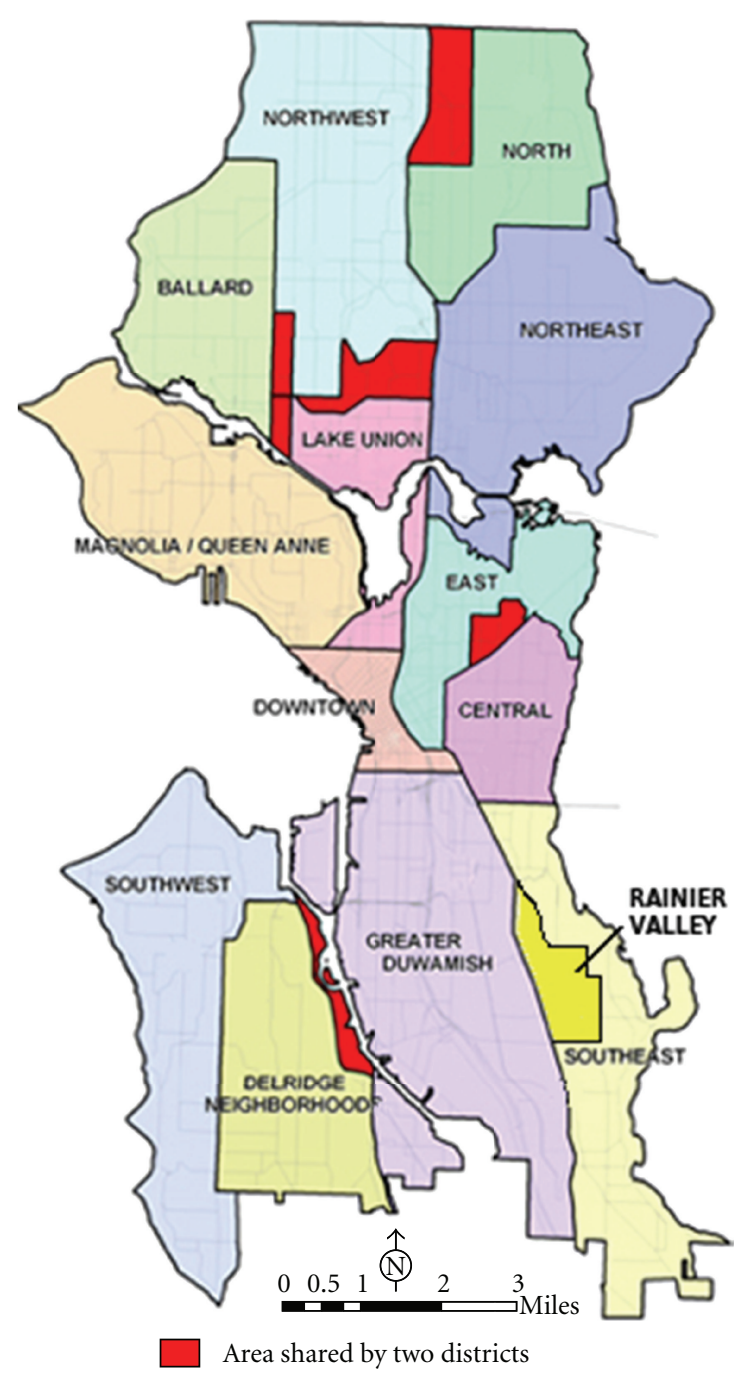

Figure 1: Map of Seattle Districts and Rainier Valley Neighborhood. Source: City of Seattle.

have made Rainier Valley an attractive place for recent immigrants and lower-income communities of color [31]. Indeed, diversity in Southeast Seattle is clearly visible in the prevalence of ethnic groceries, eateries, and cultural centers along its main boulevards, Beacon Ave, and Martin Luther King (MLK) Jr. Way.

The opening of Seattle's LINK Light Rail line in July 2009 raised concerns among many citizens and city planners that the neighborhood's character may be threatened: the neighborhood's proximity to downtown, cultural diversity, and relatively low cost of land acquisition were anticipated to be powerful motivators for rising real estate prices as similar trends have occurred elsewhere [32]. Without appropriate regulation, high-priced development may indirectly increase the cost of living and working in the valley, displacing vulnerable populations [31, 32].

Despite its characteristic diversity, neighborhood advocacy in the Rainier Valley has traditionally been dominated 
by a few dedicated and well-organized neighborhood associations [9]. Though open to the public and presumably inclusive of interested parties, these organizations are traditionally run by a community of well-educated, white, single-family homeowners [10], or the "usual suspects." (The notion of "usual suspects" - or the same community representatives participating repeatedly in planning processes, often to the exclusion of others-has been documented in other urban planning contexts as well. See, for example, MacLaren et al. 2007 [7]).

Motivated mainly by these reasons, the City of Seattle implemented a process in 2009 to formally update three neighborhood plans in Southeast Seattle-specifically the neighborhoods of North Beacon Hill, North Rainier Valley, and MLK Jr. at Holly Street. The city selected these neighborhoods for updates due to a variety of reasons, but principally because of anticipated changes to community shape and character following the opening of LINK light rail in July of 2009. At the outset of the process, city officials expressed particular interest in soliciting community members' vision for development and involving diverse voices in the process [10]. Experienced city planners commented that they hoped a more inclusive public process would encourage community members to remain actively involved during implementation of the resulting neighborhood plans.

\section{Research Questions and Methods}

Our study was driven by a central research question: How did the trusted advocates model of outreach affect the process and outcome of planning efforts in Seattle's Rainier Valley neighborhood? Supporting questions included (1) How was the planning process conducted? (2) Who was (or was not) involved? Specifically, did the process involve a larger number and a greater diversity of people than previous iterations? (3) What were the proposed methods of implementation? (4) How were the new outreach model and the traditional public planning process used in parallel or collaboratively?

We collected data through interviews and direct observation of the planning process during September and October of 2009. Forty semistructured interviews with representatives of a range of organizations and perspectives were conducted. Interviewees included 17 city employees; 5 faculty members from the University of Washington's (UW), Department of Urban Planning and Design; 8 representatives from community development organizations; 7 residents and local business owners; 3 private land developers involved in southeast Seattle.

We selected interview subjects based on their relevant experience with and involvement in the neighborhood planning process as well as their familiarity with the community. An effort was made to coordinate interviews with representatives from all effected neighborhood associations, collaborating city agencies, key participants in the original neighborhood plans, and residents who felt personally effected by the POL engagement process. A request to the city to facilitate access to the liaisons was declined. Those POLs who were contacted based on introductions through and recommendations from other interviewees were not responsive to interview requests.

Following a semistructured, interview-guide approach [33], we initiated the interviews using several consistent themes. All interviewees were asked to discuss their prior involvement in neighborhood planning in Seattle; familiarity with the new POL-based strategy of soliciting community participation and perception of its relative success and potential for replication; perception of the relative value of a special outreach process based on empowerment of traditionally underrepresented ethnic groups.

We then posed questions specific to the interviewees' position or area of expertise, historic involvement in Seattle planning, and recent involvement in the POL/traditional participation process. For example, discussions with city staff focused primarily on the motivations for implementing the new trusted advocates process and the historical background related to updating the Neighborhood Plans. UW faculty members were asked to reflect on the process in Seattle from an academic perspective, including the costs and benefits of deliberate inclusion; the perceived value of community participation; the ethical responsibility of government to maintain diversity in communities undergoing rapid development as a result of public investment. Finally, interviews with residents and local business owners focused on the interviewees' visions for the neighborhood and neighborhood planning process, including their perceptions of the value of ethnic diversity in the community and the efficacy of the POL process in involving a diversity of community members. In asking these questions, we sought to understand in part the degree to which a network had begun to form between the usual suspects and those recently empowered. We also inquired about residents' perception of local government's intentions in conducting the neighborhood plan updates.

Additional data were collected through observation at two open house meetings hosted by the City of Seattle at the Asian Counseling and Referral Services in Mount Baker in late September. As a participant-observer, the lead author collected data on the format and structure of the event, as well as the demographics and demeanor of its attendees. Informal discussions with citizens and city staff augmented data collected through observation of participant commentary.

We analyzed the aforementioned data using a thematic analysis process [34] organized through the qualitative data software package NVivo8. We created coding categories based on emergent properties of the data, direct observation of the planning process, and literature provided by the City of Seattle describing the planning process. Particular attention was paid to those subjects most critical to an effective public outreach process, as defined by the literature: POL recruitment and training, culturally appropriate outreach techniques to overcome barriers to representation by traditionally underrepresented groups, efforts to empower local groups that are traditionally disempowered, efforts to build relationships between distinct community groups, and intended strategy for implementation $[2,5,17-19,27]$. 


\section{Findings: History, Inclusivity, and Plan Development in Southeast Seattle's Neighborhood Planning Process}

In this section, we present the data collected through interviews, observation, and documentary review via a narrative interweaving multiple perspectives from the range of data sources. We begin by describing the historical background of the neighborhood planning process as well as implementation of the 2009 process. We then discuss Seattle's Race and Social Justice Initiative, which impacted the planning process and inspired the engagement of POLs. Lastly, through the use of a theoretical lens, we examine the outcomes of the process, perceived problems, and potential solutions for "bridging the gaps" and improving the process of the trusted advocate model.

5.1. The History of Neighborhood Planning in Seattle. Following adoption of a 20-year comprehensive plan entitled Toward a Sustainable Seattle in 1994, the Seattle City Department of Neighborhoods facilitated the creation of neighborhood plans in 38 geographically defined communities throughout the city [10] (see Figure 1). Framed as a "visioning process" to inform future development, the city solicited broad goals for the community, as well as specific appeals for improvements to transportation infrastructure, housing stock, and land use code [10]. Interested residents and local business owners from each of the 38 communities convened to form Neighborhood Plan Steering Committees, bodies with considerable autonomy in overseeing the planning process for each neighborhood. The city assigned neighborhood planners to support each steering committee and to act as liaisons to city departments and provided $\$ 30,000$ for professional assistance in the creation of plans as well as additional funds for outreach materials [10].

From 1995 to 1999, the steering committees sought input from their neighbors via traditional means of engagementworkshops and large public meetings [10]. The city distributed only limited guidelines for the plans, leading to considerable inconsistency in their structure and organization. Since neighborhood residents demonstrated differing degrees of experience and commitment, the resultant neighborhood plans varied greatly in detail, feasibility, and expertise. Nevertheless, the Seattle City Council formally recognized the neighborhood plans in 1999 [35]. Relevant city departments then compiled a list of requests from each neighborhood for review and response, releasing an adoption matrix with individualized feedback on project feasibility and tips for implementation [10].

\subsection{Critique of the Original Neighborhood Planning Process} and Plan Implementation. Participants in the original planning process expressed concerns that the Neighborhood Plan Steering Committees did not have representative diversity. A report from the Department of Urban Design and Planning Studio at UW also criticized the lack of socioeconomic and ethnic diversity in the original neighborhood planning process [9]. One senior city staff member remarked, "Going to nighttime meetings is kind of an upper-white middle class thing. It takes having a full daytime job, and probably a spouse who can be home with the kids." Particularly in areas of Southeast Seattle with large minority and immigrant populations, interviewees suggested that many communities of color remained unaware of or disengaged from the process of neighborhood planning.

Even those members of minority communities with the inclination to participate in the planning process experienced significant barriers. Meetings were inaccessible to most foreign language speakers; planning jargon was frequently employed; discourse was sometimes biased towards community members with preexisting relationships to city staff. Prior studies have reported similar barriers to participatory processes $[1,2,13-15]$, which can create conditions that privilege certain groups. Research suggests that the inability of disadvantaged groups to access participation avenues and sustain advocacy efforts may be linked to the dearth of resources they possess relative to other urban groups, such as white, middle-class residents, that is, access to information and decision makers, knowledge of bureaucratic processes, and ability to attend frequent meetings [1]. According to a UW professor who advised a number of neighborhoods on their original plans, the format for soliciting community opinion was inherently flawed, "Throughout the nineties it was [about] who had the staying power to fight for this item or that item, and I think it wore down a lot of people...."

Interviewees perceived that limited participation in the planning process led to inequitable allocation of resources during the implementation stage: those who had been economically disadvantaged or politically uninvolved remained underserved. A UW professor with a history of involvement in neighborhood plans commented, "If I'm a recent immigrant from fill-in-the-blank country where confronting government in any way, shape or form may actually endanger my health, I am less inclined to take part in neighborhood matching grants." For people who have lived under governments that "deny or repress citizen participation" power can be perceived as a "monolithic" and unchanging force, a view that can "paralyze effective analysis and action" [36, page 39].

The plan implementation faced significant challenges. Between 1999 and 2002, the city maintained six neighborhood development managers (called "sector managers") charged with oversight of Neighborhood Plan implementation and internal advocacy for the plans within city hall. In 2002, the sector manager roles were eliminated, causing concern among neighborhood advocates about the loss of a direct link to the city. One affordable housing developer said, "Firing the sector managers was a real loss for neighborhoods in terms of having someone at the city that they felt like they could really rely on and trust to implement part of their plan." A former neighborhood development manager commented that, "[The city] lost the continuity, the consistency, the accountability and the transparency [of the planning process]."

Without a direct link to the city, support for execution of the neighborhood plans began to lose momentum. Following the elimination of the sector managers, the 
responsibility for neighborhood plan advocacy was assigned to the Neighborhood Stewardship Councils, a reincarnation of the original steering committees. Some participants in the process contend that the shifting of responsibility from the neighborhood development managers to the Neighborhood Stewardship Councils alienated many of the municipal allies of the process and also disrupted a critical avenue of communication between neighborhood advocates and the city government. In addition, the new structure of the relationships made it more challenging for city officials to understand on-the-ground needs of the communities. A Department of Transportation employee noted that, "These neighborhood plan recommendations were, to a certain extent, seen as kind of externally directed. So the departments knew that they had to do this, but to a certain extent, the whole realm of Neighborhood Plan implementation was kind of on the margins."

A UW faculty member, who conducted a survey of Seattle's Neighborhood Stewardship Councils in 2001 posited that the extended, iterative nature of plan development limited enthusiasm for ongoing involvement in implementation. "A number of [the planning efforts] were doing okay, but people had worn themselves out. And I think the people who put so much time and energy into the neighborhood planning process hoped or expected that some new blood would come forward and do the implementation. And in most cases, that just did not happen.”

Finally, several planners and "usual suspects" expressed concern over the "piecemeal" approach to neighborhood planning in the last ten years. Even as the majority of neighborhood plan projects were executed (70\% according to a City of Seattle employee), many felt the sum of those elements often did not effectively embody the community's collective vision for the neighborhood. Arnstein [18] suggests that community members may participate in the design of plans but if these plans are later perceived as inept or inequitable in their implementation, they may fail to engage community members in a meaningful way in the long term. A neighborhood advocate noted that inclusive planning is only effective if coupled with city leadership on plan development and implementation, "If there's no baseline for 'This is what we want for our city, from city government then it does not matter how many community representatives go out and work with people and get their opinions and input, if there is nothing to integrate those feelings and thoughts and opinions into a plan to actually get anything done, then it is sort of a waste of time. And again, it's an alienating thing, because people feel like, 'well I went to meetings, I talked to people and nothing has changed, it's all the same."'

In 2007, the City of Seattle recognized the need to update the original neighborhood plans in a more effective, inclusive way $[37,38]$. When the city designed a plan for public engagement, they adopted a different strategy - that of the trusted advocates model borrowed from public health [23]. The city-led process was designed to engage more diverse and representative voices from the community, while still allowing increased government oversight of development and feasibility of implementation. City officials hoped this approach would empower new leadership within the com- munity and strengthen links between local government and minority communities [37].

\subsection{Updating the Plans: Seattle's Race and Social Justice} Initiative and Use of Planning Outreach Liaisons. In 2009, the City of Seattle undertook a process to update the 1995 neighborhood plans of three Rainier Valley communities: North Beacon Hill, North Rainier Valley, and Martin Luther King Jr. at Holly Street (Othello). In accordance with the goals of the city's comprehensive plan, Seattle opened a north-south light rail line in July of 2009, running through the Rainier Valley. Given the region's proximity to the downtown area and relatively low cost of land acquisition, citizens, city planners, and community activists, among others, voiced considerable concern that continued rising costs of living may lead to displacement of many of the neighborhood's lower-income as well as racially and ethnically diverse residents and business owners. Indeed, a migration of people of color from downtown Seattle to the southern suburbs of Kent and Tacoma has already been noted in demographic shifts [31].

Following the launch of Mayor Greg Nickels' Race and Social Justice Initiative in 2008, wherein the city committed itself to ending institutionalized racism, the city elected to pilot an adapted version of the trusted advocates model for outreach during neighborhood plan updates [10, 37]. The city's model, adapted from a strategy used by a number of city employees in conjunction with the Annie E. Casey Foundation for health promotion in White Center, Seattle [23], relies on city-contracted planning outreach liaisons (POLs) to facilitate civic involvement within their respective communities. The POL engagement process was to run parallel to the traditional outreach process of holding open houses and public meetings to engage the usual suspects in the three Southeast neighborhoods where plans were being updated.

In the Rainier Valley, 13 communities were identified as "traditionally underrepresented" groups and targeted for increased involvement during neighborhood plan updates: African American; native American; seniors and people with disabilities, youth; Latino; Oromiffa-speaking (Ethiopian); Amharic-speaking (Ethiopian); Cambodian; Chinese; Tigrinya-speaking (Ethiopian and Eritrean); Filipino; Vietnamese; Somali [10]. The neighborhood plan outreach specialist explained: "The idea is that you take someone from the community who is bilingual and bicultural, who is someone who is well-respected in the community, does not have any strong political affiliations in the sense that maybe one faction of the community is subsequently, you know, disinterested in participating."

5.3.1. Outreach: Recruiting and Training the POLs. Rather than publicly announcing the POL position, city staff relied on cultural centers and community groups as venues for recruitment of qualified candidates. According to city staff, the desired qualifications included (1) experience in outreach and community organizing, (2) experience with facilitation, and (3) knowledge of where their community meets and gathers. Given the city's objective to engage as 
many additional stakeholders as possible, it was critical that POLs be capable and comfortable reaching out to all facets of their community. This proved to be challenging in certain communities-for example, three different languages are spoken within the Ethiopian community alone. Previous knowledge of urban planning was not required, as basic training would be included for all hired POLs.

In addition to cultural sensitivity, facilitation and leadership skills were highly valued throughout the hiring process. Those with prior facilitation experience-schoolteachers, political leaders, and community advocates-were among those selected. According to the neighborhood planning outreach specialist interviewed, the role of each POL was "to explain why it was important for these underrepresented communities to be involved in the planning process. As someone who has not traditionally been engaged in the civic process, why did it matter now? The answer to that question was different for each community, which explains both the challenges and benefits of the trusted advocate model."

POLs, as indigenous leaders, are uniquely positioned to understand the relevance of neighborhood planning in their community. They are equipped with the language skills, cultural literacy, and environmental familiarity needed to act as liaisons to their constituents [25]. For example, many participants expressed the need for a culturally appropriate community center. City staff determined that resources could be made available for a flexible, multiuse space that is designed to be culturally sensitive to each community group. A Cambodian POL could then articulate this opportunity to members of the Cambodian community and report on the specific needs of his/her constituency. This approach is necessarily limiting, however. As the same POL tailors his/her approach to the model Cambodian community center participant, other Cambodians may be effectively marginalized. It is difficult for a POL to tailor their approach to the many perspectives of an entire community, which comprises a variety of perspectives, values, and competing interests.

There are also caveats in the recruitment of "community leaders" as POLs. Heath notes [36] that as community health workers become more educated and move up to the middleclass, for example, they may no longer be able to identify with and provide the same help to persons of the lower socioeconomic levels in their communities. And the fact of simply working for city planners may distance POLs from their communities, possibly even antagonizing community members [25].

Although the POLs received some training to learn details of the planning process and skills for outreach, the POL model relies on the notion that community leaders are best suited to design a strategy to solicit input from their own community. However, in recruiting individuals from communities that do not typically participate in, or understand planning processes, nor have knowledge of community resources, city planners ran the risk of choosing representative with similar challenges, as suggested in the public health care literature [25]. This assumption may also contribute to bias in the results. As leaders, the POLs may be tuned into a different set of priorities than other members of their community, prioritizing big picture issues over more personal ones, such as a vital crosswalk in a busy street. During brief trainings in preparation for the outreach process, POLs were not afforded a full comprehension of the planning process and thus may have lacked appropriate sensitivity to the full range of planning concerns.

5.3.2. Inclusivity: The POL Process. The update process occurred in four phases. During Phase I, which began in fall 2008, POLs hosted over 1, 200 participants at 41 workshops in a variety of mostly small-group environments $[10,39]$. Interviewees described how POLs attended community events, hosted small dinners with culturally appropriate refreshments, and solicited feedback from their friends and families, all in their native language. The POLs sought community input in three broad categories, based on the neighborhood visions detailed in the original neighborhood plans: creating a transit-friendly town center, designing a neighborhood for life, work, and play, and moving towards sustainability. This information was then combined with input gathered from the general public at the traditional community outreach meetings and synthesized into a series of themes for further discussion [39].

In June 2009, POLs launched Phase II, a series of weekend workshops designed to expand on themes discussed in Phase I [40]. In the POL process, these workshops took the form of smaller, discussion-based meetings where POLs served culturally appropriate food. Attendees used smallscale neighborhood models to experiment with their preferences for various routes, destinations, and densities in their communities. A similar exercise was employed at the city's public open house. City planners then used this information to design blueprints for future neighborhood development in each of the three neighborhoods [40].

In September, based on their outreach and research, city staff unveiled three options for each of the three neighborhoods in Southeast Seattle [38, 39]. Large posters depicted the proposed visions through neighborhood maps, streetscapes, and 3D design guidelines in schematic form for Phase III at two large, public open houses. The POLs were present at these meetings to provide translational services and support for non-English speakers. Free childcare was available at all POL workshops and public meetings. Throughout the process, the POLs, with the support of city resources, helped overcome some of the economic and linguistic barriers commonly identified in studies on citizen participation in municipal planning processes.

5.3.3. Outcomes of the POL Process. According to city employees whom we interviewed, community response to the POLs' outreach efforts was overwhelmingly positive. Many first-time participants were first-generation American citizens or residents who hailed from countries with oppressive dictatorships; others were from cultures where the opinions of uneducated or illiterate community members were not valued. Thus, the city's mandate to solicit public involvement of underrepresented groups resulted in enhanced citizen participation and a redistribution of power consistent with findings in the literature $[18,19]$. Additionally, city 
officials began to see the POL process as an opportunity to teach civic engagement to recent immigrants and disengaged community members. Discussion in the POL workshops reached beyond the boundaries of the neighborhood plan updates. The neighborhood plan outreach manager commented, "This may be the only opportunity they have to speak to the city in their language...we do not want to miss anything." Burby [3] noted that the importance of participation can go beyond achieving the immediate goals of plan making and implementation; other reasons for involving citizens relate to the achievement of democratic principles.

\begin{abstract}
"These principles include basic concepts of fairness; the rights of individuals to be informed and consulted and to express their views on governmental decisions; the need to better represent the interests of disadvantaged and powerless groups in governmental decisionmaking; and the contributions of participation to citizenship." [3, page 35].
\end{abstract}

While the model was effective in increasing participation of underrepresented groups and may have helped achieve some democratic principles, there were limitations. Some communities were more easily accessed via the POL model than others. According to city planners, groups with inclusive cultural community centers, strong religious affiliations, and other forms of social networks demonstrated the greatest success with POL outreach. Self-organized communities, such as the Chinese, the Vietnamese, the handicapped, and seniors, coordinated their participation with relative ease and notable enthusiasm. One group, the Seattle Lighthouse for the Blind, successfully lobbied for significant modifications to the light rail station in order to support usage by the blind community.

POLs to other, less centralized communities, such as the African-American community, the Latino community, and youth, struggled to yield a representative sample of the population. In some cases, city staff felt the POL fell short of expectations. One in particular struggled to network within a dominant religious community in which she did not take part. Her detachment from the social fabric of the community limited her capacity for soliciting thoughtful dialogue. In other communities, there were inherent challenges to widespread engagement. According to city staff, African American participation suffers from poor historic relationships with government, and youth are notoriously challenging to engage. Thus, POLs were able to successfully engage some stakeholders from traditionally underrepresented communities in the neighborhood planning process, However, their capacity to build relationships across competing groups and facilitate new links to community resources appears to depend largely on the nature of the community and the degree to which the community members identify with the POL.

POLs were hired to facilitate community participation in all three neighborhoods; no distinction was made between Beacon Hill, North Rainier, and MLK at Holly Street (Othello). This lack of attention to diversity on microscales led to some ambiguity in the goals of engaging underrepresented groups within specific neighborhoods. As one community activist put it: "One of the issues is who gets to be a stakeholder? And does interest make you a stakeholder?"

Participation by nonresidents in some of the meetings was another issue according to the same community activist. "At the second neighborhood plan workshop, I was at a table with...probably 10 Vietnamese speaking folks with a translator...Well, as we talked about this and that and the other, it turned out that they all live in Kent, and they come to shop at King Plaza. So did we access local Vietnamese folks? Not that I could tell. Should they have input? Sure. Do they represent the Othello Vietnamese community? Maybe...So was it successful? I don't know."

5.4. Collaboration: Critiques from the Usual Suspects. The POLs secured unprecedented involvement from many previously underrepresented communities [40]. During Phase I of the 2009 Neighborhood Plan Updates, POLs hosted 41 workshops throughout Southeast Seattle and the Greater Duwamish, which were attended by 1200 participantsstemming from 16 traditionally under-represented communities [40]. Nonetheless, a number of interviewees suggested that the outreach process was contentious among some of the "usual suspects" involved in the traditional outreach process. Interview data suggested that awareness of the POL model, and its corresponding principles of inclusivity, was surprisingly limited amongst the usual suspects. In sharp contrast to the original neighborhood planning process, the update process was overseen directly by city planners and administrators. Research has shown that the decision planners make about public involvement that can affect participation and the development of "plans that matter" [3, page 35]. In this case, the choice of city planners to separate the POL process from the one used to interact with the usual suspects, as well as a lack of communication around what was happening, led to frustration by long-term neighborhood advocates. Several stewards of the original plans expressed confusion and frustration at the lack of transparency surrounding city goals for the update process, as well as the goals and design of the POL process.

The greatest cause of complaint from long-term neighborhood advocates derived from the shift in approach adopted by the city during Neighborhood Plan Updates relative to the traditional process used for creating the original plans in 1999. The chair of a prominent community organization commented, "The city didn't explain why [the planning process] was different, but the demographics are different, the political situation is different, the finances are different. It's ten years later, why would it be the same?" The principal neighborhood planning manager at the city noted, "To my surprise, the discussion and the friction [with usual suspects] was about control and power and not about the specifics of the actual planning work. There was certainly some disagreement, a variety of opinions in terms of priorities of the plans, but by a huge margin, what people really focused on is who speaks for the neighborhood." One community leader indicated that he was more interested 
in the processes' outcome than the city's motivations: "If they're good ideas, I don't care where they come from." Based on these comments, it appears the city did not incorporate an understanding and analysis of power relationships and interests into the new neighborhood planning process, which "can lead to missed opportunities and poor strategic choices" [36, page 39]. In this case, it caused friction and may have prevented collaboration among the usual suspects and those new to the process.

According to a number of the participants involved in the parallel process, public knowledge of the "actual planning work" from the POL process was limited. In early 2009, city representatives gave brief presentations on the intended structure of the POL model to most local neighborhood associations. However, beyond those meetings, very little information on the POL process was released until July 2009. Several citizen groups, including the Neighborhood Planning Advisory Council (NPAC), requested reports from planners and POLs in the spring of 2009 but received no response until July, when a brief report of themes from the POL meetings was released. Several members of NPAC, an organization created in accordance with a City of Seattle resolution in September 22, 2008, with a mandate to "make recommendations and provide on-going guidance to the Executive and Council on the development of the Neighborhood Plan Status Reports and the Neighborhood Plan Update Process" [41] expressed frustration due to poor communication and insufficient time allowed by city officials during the update process. We have elected to discuss NPAC involvement only minimally in this paper, as our intended focus is the POL process. The lack of a formal process to ensure transparent communication between traditionally engaged citizens, newly enfranchised participants, and city staff fueled distrust in the neighborhoods. A longtime community activist said, "I don't know what the motivations of the city were. I'm open-minded. I think more participation is good but it clearly caused certain people who were traditionally in the driver's seat to feel displaced and pissed off." An opportunity to bridge the critical gap between minority groups and usual suspects and thereby facilitate the collective decision making considered central to consensusbuilding [20] was neglected; the resultant tension was evident in interviews with community members.

City staff argued that a clear division between the two processes was intentional. One explanation given was as follows. "When you're trying to get new people into a process and you have somebody who is very confident and knows the system and is using lots of lingo, it can be very intimidating. That's why having as many venues as possible is important." Through this approach, citizen power was essentially redistributed, enabling traditionally disempowered and excluded citizens to be included and be heard [18].

The city "brought a willingness to let go of the traditional meeting-style approach, which meant that not everybody got to hear the same discussion." Unfortunately, as one NPAC member noted, poor communication can breed distrust. For example, at one point, a rumor spread that one outreach liaison was not from Seattle. A long-time neighborhood activist remarked, "I think a lot of times when they do stuff like that, people like me are suspicious because they got to specific places and specific groups...Why is it more important to develop that [ethnic or social] group than any other group? Why do we have to be groups?"

Part of the concern stemmed from the city's decision to delay discussion of residential density, according to representatives from NPAC and other neighborhood advocates. A number of citizens criticized the city's transparency around plans to upzone during Phase I and Phase II. One citizen who was interviewed made the following comments with regard to the process: "I was amazed. There had been no discussion of density or height until the last meeting. Suddenly, they've got these three scenarios of different height and no explanation, no detail of what it would really mean. That came out of nowhere. That made me think, 'Oh my God, all the critics are on to something here. They're just going to upzone these areas and say, "Look at all the people we involved." " In contrast, the city believes they were clear about their intention to upzone. A representative from the mayor's office commented, "We were clear we wanted more density...we were clear that we were leveraging the investments made by the housing authority and the light rail."

Several residents of Rainier Valley expressed their dismay at the equally weighted inclusion of non-residents in neighborhood planning outreach. As noted above, there is evidence that a few POLs invited commentary from citizens who neither live nor work in the relevant communities, but occasionally shop or recreate in the area. This issue raises questions about the fundamental purpose of neighborhood planning: is it to directly benefit the residents of the neighborhood or to better integrate the neighborhood's design and purpose into the broader mosaic of the surrounding urban environs? The inclusion of nonresidential participants also suggests that, while there may be limitless stakeholders, a finite number of participants actually become engaged in the process, and, thus, those people may have disproportionate impact on the outcomes of the process. Greater oversight by the city in defining or limiting the communities targeted for POL outreach may have avoided this issue.

5.5. Community: Bridging the Gaps. The City of Seattle employed the trusted advocates model throughout the outreach process that accompanied the 2009 neighborhood plan updates. The goal of this new model was to encourage participation in the planning process by previously underrepresented groups. City records indicate a certain level of success. Approximately 1200 Seattle residents who had not previously attended planning meetings contributed to plan updates through the POL process. However, it appears that participation of those diverse audiences is unlikely to be sustained without adequate followup. As has been noted in other planning efforts (e.g., $[3,7]$ ), a planning document is only as strong as the community of people working to implement the articulated vision. Without ongoing support from the city and pressure for accountability from the community, traditionally underrepresented communities will remain so. As a UW professor of urban planning noted, "The original 
process, in theory, is quite good for a number of things. But it runs into a problem at the definition of what a plan is for; what the ultimate goal is. Is the plan a document for implementation or is that plan a process for neighborhood development?"

The usual suspects are also keenly aware of the challenges associated with plan implementation. A member of the Othello Neighborhood Association (ONA) lamented, "One of the difficulties, I think, with the neighborhood plan is it doesn't in and of itself have any teeth. So you get to wave it at city council meetings or at zoning board meetings, but it has no teeth." Seattle offers a number of small grant opportunities to support neighborhood action towards the implementation of these plans; however, as they cannot provide logistical support for obtaining grants or implementing projects, they must rely on the active support of a well-organized and well-educated citizenry.

At the time of this study, relationships between POLcommunities and the usual suspects remained cursory, at best. Another ONA representative was dismissive of the process, "I don't think ONA paid any attention to what was going on with the other groups. The city just did whatever they did. And I guess there were a whole bunch of folks who went out and did that. We don't really know anything about that." As previously discussed, POL outreach was intentionally sheltered from the city's traditional outreach process, undermining an opportunity to build relationships between and amongst local community networks, viewed as a key element in the successful implementation of plans [19]. Although some minority communities elected to attend citywide events, limited effort was made to build relationships and foster collective decision making between usual suspects and newly empowered residents through facilitated discussion. One city employee openly discussed the need for greater cross-process involvement: "That was one of the struggles. We had these parallel processes and at some point, we're going to have to bring these two processes together, if not actually, then at least conceptually." Various interviewees offered their suggestions for uniting the two communities through focus groups, design charettes, or public presentations from the POLs. The lack of a formal feedback loop not only bred anxiety and distrust in the neighborhoods, but it also missed the opportunity to inspire diverse coalitions of neighborhood activists, united by a similar vision for their community.

\section{Limitations and Future Studies}

This study provides valuable insight into use of the trusted advocates model in Seattle's city planning process, though several important limitations indicate the need for further study to supplement our findings. First, we spent only six weeks on site in Seattle conducting interviews and attending planning meetings. Additional depth of understanding could be gained by lengthier firsthand observation of the process.

Second, our work occurred in September and October of 2009, during Phase III of the process. This seemed to be a prescient time to be on site and conduct interviews while the process was still very fresh in the minds of our interviewees, and the city had only recently unveiled three distinct visions for the neighborhood plans. Discussion of plans for implementation, however, had only just begun. This timing presents a challenge of little time elapsing to see how implementation of the process would proceed. Conducting the interviews at a later date would also have allowed for more critical reflection over a lengthier period.

Third, although we attempted to include a diversity of perspectives, we recognize that 40 people out of the thousands who participated do not make a representative sample. Rather, our hope was to elicit thoughtful reflections on the opportunities, challenges, benefits, and drawbacks of this process so as to consider how the conduct and outcome of this process compared with those from more traditional planning exercises. Soliciting the feedback of POLs, in particular, might have shed greater light on the benefits and challenges of the POL model, as well as barriers to citizen participation in their individual communities and how these were overcome. Moreover, evaluating how community members perceived POLs and the qualities or techniques that enabled the POLs to initiate direct and sustain engagement of their communities in the planning process may help to inform recruitment of trusted advocates and improve the model's efficacy.

We recommend that future studies continue to explore questions such as what aspects of the trusted advocates model are most effective in increasing diversity among participants and in crafting plans that matter and have the greatest chance of being executed? How might the trusted advocates model address the challenges of engaging decentralized versus centralized, self-organized communities? Which techniques are most effective for sustaining involvement and advocacy as the plans are implemented? How does power distribution affect participation and the efficacy of the trusted advocates model? To what extent do underrepresented groups view the resulting plans as representative of their visions?

We believe it would also be beneficial to continue to track the implementation of the resulting updated neighborhood plans over time. Further research into the resulting plans, including their similarities to and differences from those developed using a traditional planning process, would offer insight into how inclusive processes may affect the content and execution of such planning efforts.

\section{Conclusions}

We set out to document the process by which Seattle updated its neighborhood plans in 2009, examining the trusted advocates model implemented in Southeast Seattle and contrasting it with more traditional planning processes.

Ultimately, our findings corroborate other published accounts of the process [10] in suggesting that democratic engagement was the greatest success of using the trusted advocates model - according to statistics reported by the city [40], articles (e.g., [10]), commentary from interviewees, and firsthand observation of the process, a larger and more diverse coalition of citizens was indeed involved in the 2009 
planning process than had been engaged with earlier processes. As Mazzella [10] states, "The Neighborhood Plan Updates Outreach Strategy successfully met its primary goal, which was to bring people of color and historically underrepresented communities to the planning table and provide them with the tools to meaningfully engage with other stakeholders and City staff in the effort to improve their communities."

Although the citizens' commentary and voiced preferences were not radically different from what may have been anticipated by city planners, citizens reported feeling empowered, engaged, and interested in neighborhood planning, believing that having a seat at the table was a valuable and worthwhile opportunity. Nonetheless, several issues did arise, and questions remain about the sustainability of the plans and the deeper enfranchisement of these communities. As one city representative noted, “...I think that jumping to the conclusion that the city was successful is not correct. For us to be successful, the city would have developed that relationship with all of the individuals who participated and I don't think that has happened."

The POL process helped to overcome some of barriers to participation (though not all) experienced by traditionally underrepresented groups in Seattle including language, lack of resources (e.g., childcare needs), fear of government response to criticism, and lack of familiarity with local planning processes. Initial reflections on the POL model suggest that the process may have helped foster a greater number of educated and active stakeholders-starting with the POLs themselves and extending to some of the newly involved citizens. The city's continued use of POLs for culturally appropriate engagement of newly enfranchised members might encourage their ongoing participation in implementation of the neighborhood plans [5].

Where the POL process did not meet expectations was in soliciting input of decentralized communities, that is, latinos, African Americans, and youth, indicating that the nature of the community affects participation and the efficacy of the POL model. Similarly, the POLs succeeded in bringing many constituents of their individual communities to the table and facilitating their input into neighborhood plans in Southeast Seattle, but they were not successful in establishing critical connections with the other stakeholders in the process. From conversations with city staff, it did not appear that strong communication networks had even been established amongst POLs. Greater transparency by city officials about the POL process, and more facilitated communication among the participating groups (POLs, the newly enfranchised and the usual suspects) may have helped establish relationships among these diverse stakeholders, and thereby improve the quality of decision making, both critical ingredients of consensus building [20]. Likewise, it is important for planners to incorporate an analysis of the interests and power relationships when developing citizen participation strategies [36].

Language remains a principal barrier in facilitating communication between experienced advocates and minority groups. The North Beacon Hill Neighborhood Council has applied for a city grant that would cover the cost of one inter- preter at all council meetings. Ideally, the interpreter would be trilingual (speaking Mandarin, Cantonese, and English). However, this would still leave another 57 language groups without means to convey their interests to the community, let alone fully participate in the democratic process of neighborhood planning.

Establishing effective neighborhood networks will require that the city commit to nurturing and facilitating these relationships, through openness and frequent communication about the implementation process, continued culturally appropriate engagement, and adequate resources to ensure that all citizens have access to participation avenues and are able to sustain their involvement. "One would hope that in the future, everyone would be engaged and the whole dialogue would be more fluid. We would hold a meeting and everyone would come. But we are still building that," said a representative from the mayor's office.

The true test will occur over the next five years when it becomes clearer whether participation has made a difference in plan outcomes and whether a diverse citizenry remains engaged in plan implementation. To achieve this goal, the city will need to work to unite all residents more effectively: "I would like to see unity and diversity in a sense where each [community group] is organized in their own way, in their cultural way, but networking with each other so that there is power with unity and networking," said one city employee. To this end, the trusted advocates model may serve as a tool for overcoming barriers to participation, uniting and empowering diverse cultures and interests, and achieving collective action.

\section{References}

[1] C. Howard, M. Lipsky, and D. R. Marshall, "Citizen participation in urban politics: rise and routinization," in Big-City Politics, Governance, and Fiscal Constraints, G. E. Peterson, Ed., pp. 153-159, Urban Institute Press, Washington, DC, USA, 1994.

[2] J. Hou and I. Kinoshita, "Bridging community differences through informal processes: reexamining participatory planning in Seattle and Matsudo," Journal of Planning Education and Research, vol. 26, no. 3, pp. 301-314, 2007.

[3] R. J. Burby, "Making plans that matter: citizen involvement and government action," Journal of the American Planning Association, vol. 69, no. 1, pp. 33-49, 2003.

[4] E. Ostrom, Governing the Commons: The Evolution of Institutions for Collective Action, Cambridge University Press, New York, NY, USA, 1990.

[5] P. Davidoff, "Advocacy and pluralism in planning," Journal of American Institution of Planners, vol. 31, pp. 331-338, 1965.

[6] J. L. Uyesugi and R. Shipley, "Visioning diversity: planning Vancouver's multicultural communities," International Planning Studies, vol. 10, no. 3-4, pp. 305-322, 2005.

[7] A. MacLaren, V. Clayton, and P. Brudell, Empowering Communities in Disadvantaged Urban Areas: Towards Greater Community Participation in Irish Urban Planning (Part I), Combat Poverty Agency Working Series, Combat Poverty Agency, Dublin, Ireland, 2007.

[8] C. S. King, K. M. Feltey, and B. O. Susel, "The question of participation: toward authentic public participation in public 
administration," Public Administration Review, vol. 58, no. 4, pp. 317-326, 1998.

[9] B. Born, Planning for a Successful Process: Updating Seattle's Neighborhood Plans, 2008, http://courses.washington.edu/ studio67/planning_for_a_successful_ process.pdf.

[10] T. Mazzella, "Innovative public engagement tools in transportation planning: application and outcomes," in Proceedings of the Transportation Research Board's 89th Annual Meeting, Washington, DC, USA, 2010.

[11] R. A. Irvin and J. Stansbury, "Citizen participation in decision making: is it worth the effort?" Public Administration Review, vol. 64 , no. 1, pp. 55-65, 2004.

[12] E. van Meter, "Citizen participation in the policy management process," Public Administration Review, vol. 35, pp. 804-812, 1975.

[13] J. E. Innes and D. E. Booher, "Reframing public participation: strategies for the 21st century," Planning Theory and Practice, vol. 5, no. 4, pp. 419-436, 2004.

[14] E. L. Evenhouse, "The people know best: developing civic participation in urban planning," in Paper Presented at the Breslauer Graduate Student Symposium "The Public Interest", University of California, Berkeley, Calif, USA, 2009.

[15] J. Forester, "Challenges of deliberation and participation," Les Ateliers d'Ethique, vol. 1, no. 2, pp. 20-25, 2006.

[16] S. D. Brody, D. R. Godschalk, and R. J. Burby, "Mandating citizen participation in plan making: six strategic planning choices," Journal of the American Planning Association, vol. 69, no. 3, pp. 245-264, 2003.

[17] F. Fischer, "Participatory governance as deliberative empowerment: the cultural politics of discursive space," American Review of Public Administration, vol. 36, no. 1, pp. 19-40, 2006.

[18] S. R. Arnstein, "A ladder of citizen participation," Journal of the American Planning Association, vol. 4, pp. 216-224, 1969.

[19] J. P. Kretzmann and J. L. McKnight, Building Communities from the Inside Out: A Path Toward Finding and Mobilizing a Community's Assets, Institute for Policy Research, Evanston, Ill, USA, 1993.

[20] J. E. Innes, "Planning through consensus building: a new view of the comprehensive planning ideal," Journal of the American Planning Association, vol. 62, no. 4, pp. 460-472, 1996.

[21] S. Stall and R. Stoecker, "Community organizing or organizing community? Gender and the crafts of empowerment in gender and social movements," Gender and Society, vol. 12, no. 6, pp. 729-56, 1998.

[22] N. Salafsky, R. Margoluis, K. H. Redford, and J. G. Robinson, "Improving the practice of conservation: a conceptual framework and research agenda for conservation science," Conservation Biology, vol. 16, no. 6, pp. 1469-1479, 2002.

[23] Annie E. Casey Foundation, "Trusted advocates: a multicultural approach to building and sustaining resident involvement," Series from the Technical Assistance Resource Center of the Annie E. Casey Foundation and the Center for the Study of Social Policy, 2007, http://www.aecf.org/upload/PublicationFiles/trustedadvocate.pdf.

[24] M. A. Nemcek and R. Sabatier, "State of evaluation: community health workers," Public Health Nursing, vol. 20, no. 4, pp. 260-270, 2003.

[25] P. T. Giblin, "Effective utilization and evaluation of indigenous health care workers," Public Health Reports, vol. 104, no. 4, pp. 361-368, 1989.

[26] I. SenGupta, "Principal 5: there is clear, open and accessible communication between partners, making it an ongoing priority to listen to each need, develop a common language, and validate/clarify the meaning of terms," in Principles of
Good Community-Campus Partnerships, Community Campus Partnership for Health, pp. 41-46, 1998, http://depts.washington.edu/ccph/principles.html\#principles.

[27] N. Ashan, Sustaining Neighborhood Change: The Power of Resident Leadership, Social Networks, and Community Mobilization, Baltimore, Md, USA, Annie E. Casey Foundation, 2008, http://www.aecf.org/ /media/PublicationFiles/Authentic_guide_r14.pdf.

[28] City of Seattle, Department of Planning and development, Seattle's Population and Demographics, 2000, http:// www.cityofseattle.net/dpd/Research/Population_Demographics/Census_2000_Data/Data_Maps_for_Locally_Defined_Areas/DPDS_007015.asp.

[29] City of Seattle, Parks and Recreation, Seattle Parks and Recreation Census 2000: A Demographic Overview of Seattle's Communities, 2006, http://cityofseattle.net/PARKS/Publications/Census/2000/Report.pdf.

[30] City of Seattle, Department of Planning and Development, Characteristics of Language Neighborhood Districts. Characteristics of Language Census 2000: Summary File 3, 2000, http:// www.cityofseattle.net/dpd/cms/groups/pan/@pan/documents/web_informational/dpds_007708.pdf.

[31] R. Morrill, "Gentrification, class and growth management in Seattle, 1990-2000," in Global Perspectives on Urbanization, G. Pomeroy and G. Webster, Eds., University Press of America, Lanham, Md, USA, 2008.

[32] S. Pollack, B. Bluestone, and C. Billingham, "Maintaining diversity in America's transit-rich neighborhoods: tools for equitable neighborhood change," A Report prepared by the Dukakis Urban and Regional Policy at Northeastern University, Rockefeller Foundation, Boston, Mass, USA, 2010.

[33] M. Q. Patton, Qualitative Evaluation and Research Methods, Sage, Newbury Park, Calif, USA, 2nd edition, 1990.

[34] S. J. Taylor and R. Bogdan, Introduction to Qualitative Research Methods: The Search for Meanings, John Wiley \& Sons, New York, NY, USA, 3rd edition, 1998.

[35] City of Seattle, Department of Neighborhoods, Neighborhood Plan Areas, 2011, http://www.cityofseattle.net/neighborhoods/npi/plans.htm.

[36] L. VeneKlasen and V. Miller, "Power and empowerment," in A New Weave of Power, People \& Politics: The Action Guide for Advocacy and Citizen Participation, pp. 38-59, 2007, http:// www.justassociates.org/ActionGuide.htm.

[37] City of Seattle, Department of Neighborhoods, Community Feedback Report: On Process for Neighborhood Plan Updates, 2008, http://www.seattle.gov/neighborhoods/pubs/cfr042208 .pdf.

[38] City of Seattle, Department of Planning and Development, Neighborhood Planning Overview, 2010, http://www.cityofseattle.net/dpd/Planning/Neighborhood_Planning/Overview/.

[39] City of Seattle, Department of Planning and Development, Neighborhood Plan Updates, 2010, http://www.cityofseattle. net/dpd/Planning/Neighborhood_Planning/NeighborhoodPlanUpdates/default.asp.

[40] City of Seattle, Department of Planning and Development, Neighborhood Plan Update-Planning Outreach Liaison: Community Workshops, 2009, http://www.cityofseattle.net/dpd/ cms/groups/pan/@pan/@plan/@neighborplanning/documents/web_informational/dpdp017744.pdf.

[41] City of Seattle, City Clerk's Online Information, City of Seattle Legislative Information Service: Resolution Number: 31085, 2008, http://clerk.ci.seattle.wa.us. 


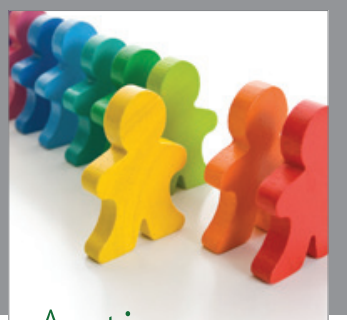

Autism

Research and Treatment
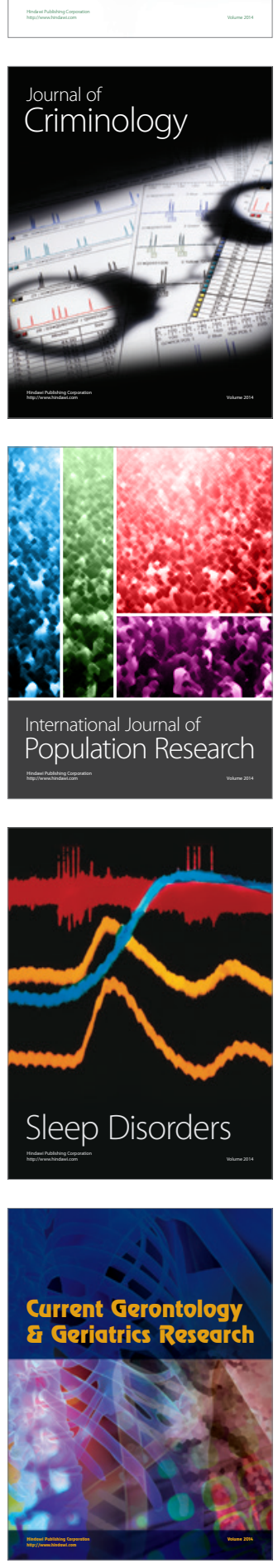
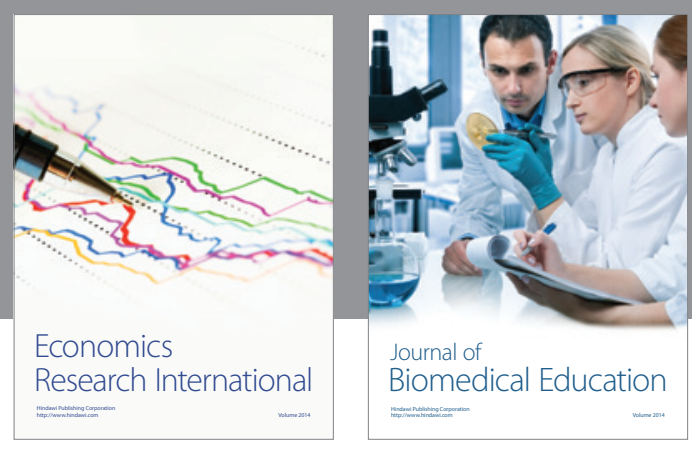

Journal of

Biomedical Education

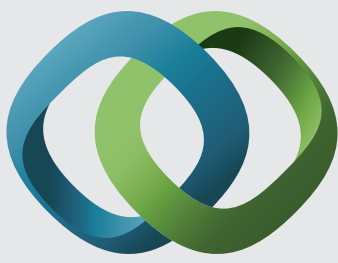

\section{Hindawi}

Submit your manuscripts at

http://www.hindawi.com
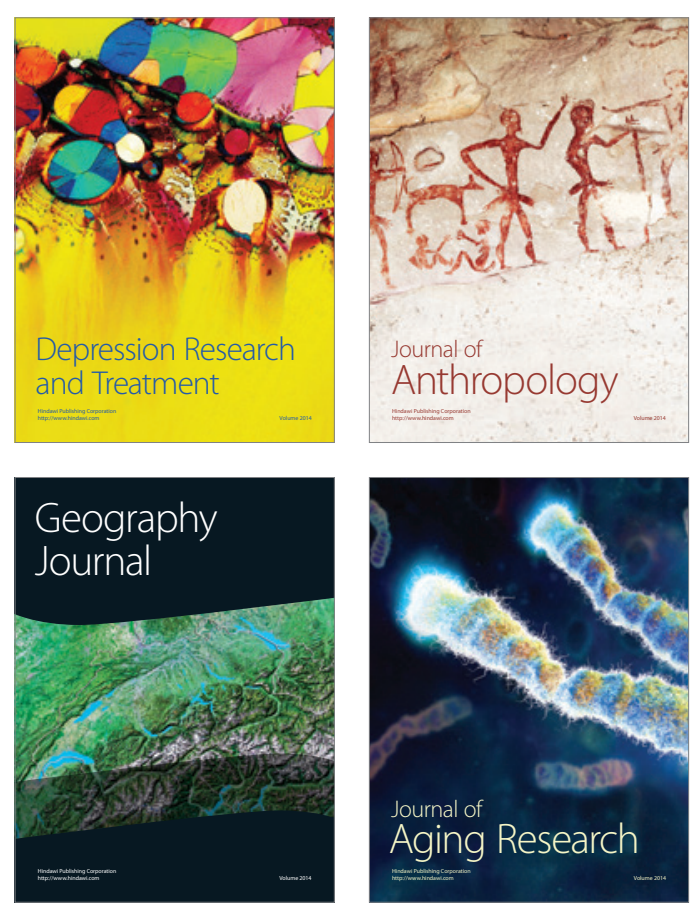

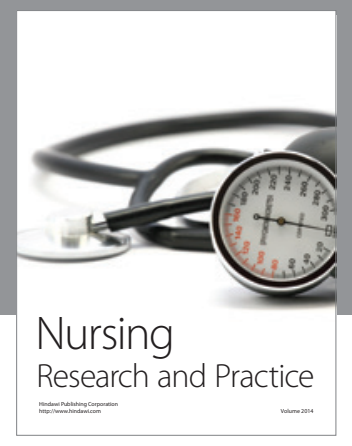

Nursing

Research and Practice

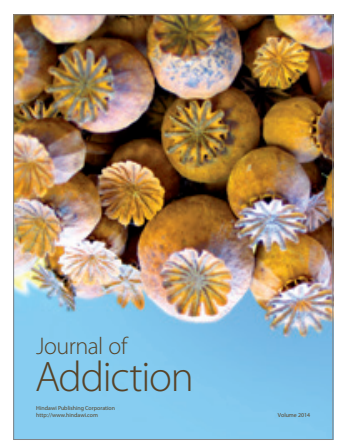

Child Development

Research

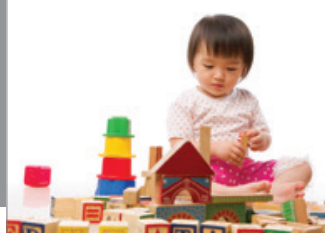

迥
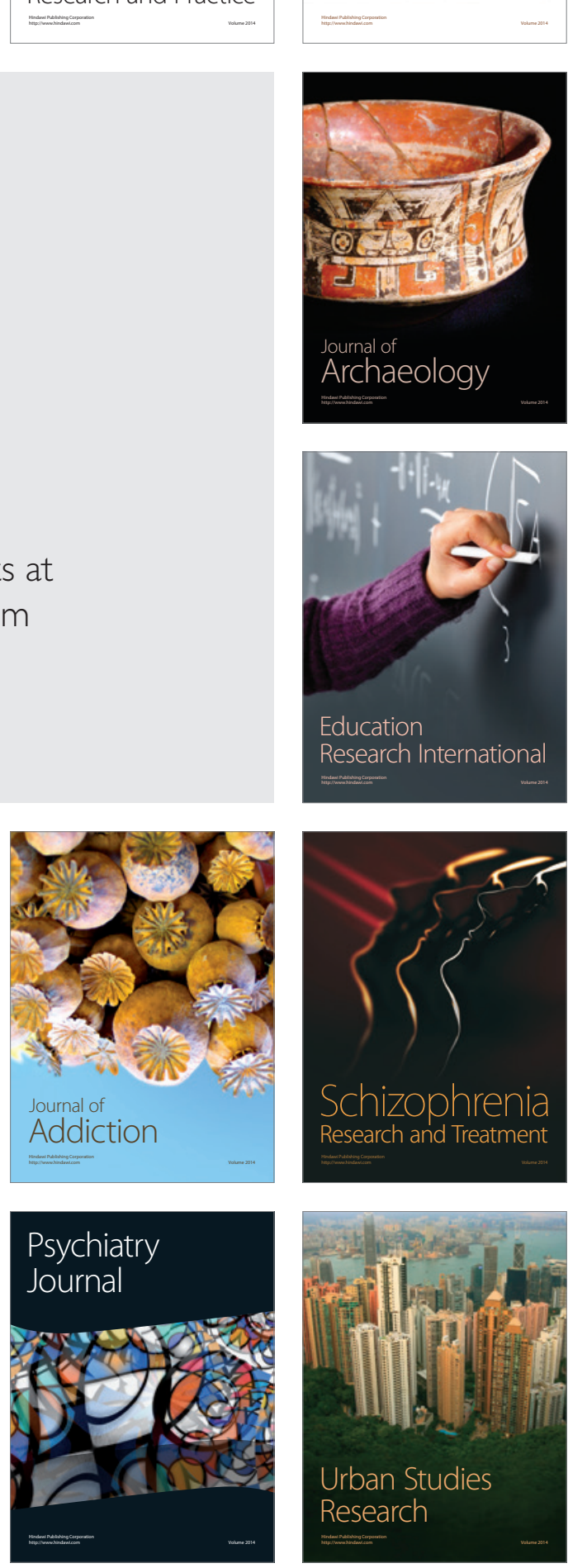